Marquette University

e-Publications@Marquette

School of Dentistry Faculty Research and

Publications

Dentistry, School of

4-2018

\title{
The Effect of Partially Exposed Connective Tissue Graft on Root-Coverage Outcomes: A Systematic Review and Meta-Analysis
}

\author{
Austin Dodge \\ Marquette University \\ Jeffrey Garcia \\ Marquette University \\ Paul Luepke \\ Marquette University, paul.luepke@marquette.edu \\ Yu-Lin Lai \\ Taipei Veterans General Hospital \\ Moawia M. Kassab \\ Marquette University, moawia.kassab@marquette.edu
}

See next page for additional authors

Follow this and additional works at: https://epublications.marquette.edu/dentistry_fac

Part of the Dentistry Commons

\section{Recommended Citation}

Dodge, Austin; Garcia, Jeffrey; Luepke, Paul; Lai, Yu-Lin; Kassab, Moawia M.; and Lin, Guo-Hao, "The Effect of Partially Exposed Connective Tissue Graft on Root-Coverage Outcomes: A Systematic Review and Meta-Analysis" (2018). School of Dentistry Faculty Research and Publications. 277.

https://epublications.marquette.edu/dentistry_fac/277 


\section{Authors}

Austin Dodge, Jeffrey Garcia, Paul Luepke, Yu-Lin Lai, Moawia M. Kassab, and Guo-Hao Lin

This article is available at e-Publications@Marquette: https://epublications.marquette.edu/dentistry_fac/277 
Marquette University

e-Publications@Marquette

\section{School of Dentistry Faculty Research and Publications/School of Dentistry}

This paper is NOT THE PUBLISHED VERSION; but the author's final, peer-reviewed manuscript. The published version may be accessed by following the link in the citation below.

European Journal of Oncology Nursing, Vol. 026, No. 2: 84-92 (2018). DOI. This article is (C Wiley and permission has been granted for this version to appear in e-Publications@Marquette. Wiley does not grant permission for this article to be further copied/distributed or hosted elsewhere without the express permission from Wiley.

\section{The effect of partially exposed connective tissue graft on root-coverage outcomes: a systematic review and meta-analysis}

Austin Dodge

Department of Surgical Sciences, Marquette University School of Dentistry, Milwaukee, WI Jeffrey Garcia

Department of Surgical Sciences, Marquette University School of Dentistry, Milwaukee, WI Paul Luepke

Department of Surgical Sciences, Marquette University School of Dentistry, Milwaukee, WI Yu-Lin Lai

Department of Periodontology, Department of Stomatology, Taipei Veterans General Hospital, Taipei, Taiwan Moawia Kassab

Department of Surgical Sciences, Marquette University School of Dentistry, Milwaukee, WI Guo-Hao Lin

Department of Surgical Sciences, Marquette University School of Dentistry, Milwaukee, WI 


\section{Abstract}

The aim of this systematic review was to compare the root-coverage outcomes of using a partially exposed connective tissue graft (CTG) technique with a fully covered CTG technique for root coverage. An electronic search up to February $28^{\text {th }}, 2017$, was performed to identify human clinical studies with data comparing outcomes of root coverage using CTG, with and without a partially exposed graft. Five clinical studies were selected for inclusion in this review. For each study, the gain of keratinized gingiva, reduction of recession depth, number of surgical sites achieving complete root coverage, percentage of root coverage, gain of tissue thickness, and changes of probing depth and clinical attachment level were recorded. Meta-analysis for the comparison of complete root coverage between the two techniques presented no statistically significant differences. A statistically significant gain of keratinized tissue in favor of the sites with an exposed CTG and a tendency of greater reduction in recession depth were seen at the sites with a fully covered CTG. Based on the results, the use of a partially exposed CTG in root-coverage procedures could achieve greater gain in keratinized gingiva, while a fully covered CTG might be indicated for procedures aiming to reduce recession depth.

Gingival recession is characterized by displacement of the gingival margin apically from the

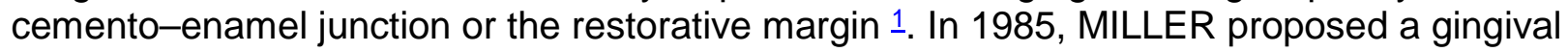
recession classification system that characterized recession into four classes that was dependent on the location of the recession in relation to the mucogingival junction and the presence of periodontal supporting tissues 2 . This classification also provides clinicians with a guideline for therapeutic prognosis. For Class I and Class II recessions, complete root coverage is achievable; however, for a Class III defect, partial root coverage might be achieved.

Studies $\underline{1}, \underline{3}$ have shown that the prevalence of gingival recession has been steadily increasing since the 1980s. The National Health and Nutrition Examination Survey (NHANES) III $\underline{3}$ reported that 23.8 million people in the USA (22.5\% of the population at the time) had one or more tooth surfaces with $\geq 3 \mathrm{~mm}$ of gingival recession. Similarly, KASSAB \& COHEN 1 reported that over $50 \%$ of the population have one or more sites with gingival recession. This rise in recession rates is a concern for clinicians because root exposure may lead to dentinal hypersensitivity, esthetic concerns, and hygiene difficulties in areas where dental plaque and calculus easily accumulate beneath and around areas of recession $\stackrel{4}{.}$.

Understanding the etiology of a disease is essential to its treatment because etiologic factors should be addressed to ensure long-term success and stability of root-coverage procedures. HALL $\underline{5}$ reported inadequate attached gingiva, high frenulum attachment, malposition of teeth, and osseous dehiscence as the predisposing factors of gingival recession; in addition, vigorous toothbrushing, laceration, recurrent inflammation, and iatrogenic factors are reported as the precipitating factors of gingival recession.

To treat gingival recession, many procedures have been proposed and utilized, including coronally advanced flap (CAF) $\underline{6}$, lateral positioned flap $\underline{7}$, double papilla flap $\stackrel{8}{6}$, semilunar flap $\underline{9}$, free gingival graft $\underline{10}$, subepithelial connective tissue graft (CTG) $\stackrel{11}{ }$, tunneling procedure $\underline{12}$ in combination with different grafting materials, including the use of CTG, acellular dermal matrix $\underline{13}$, or xenograft materials, and the use of biologic agents such as enamel matrix derivative and platelet-derived 
growth factor $\underline{14}$. Among them, CTG-based procedures have been reported to be the gold standard for root coverage $\underline{15}$.

Although the need for a wide band of keratinized gingiva is controversial, some studies have shown its importance for maintaining gingival health $\underline{16}, \underline{17}$. It has also been reported that a narrow zone of keratinized mucosa is associated with a higher incidence of gingival inflammation in teeth with subgingival restorations $\underline{17}$. As such, an alternative to gain keratinized tissue and achieve complete root coverage during root-coverage procedures was proposed in which part of the CTG is left exposed at the coronal portion of the recession defect $\underline{18}$. Thus, the purpose of this systematic review and meta-analysis was to investigate whether a partially exposed or fully covered CTG procedure influences root-coverage outcomes in the treatment of gingival recession.

\section{Material and Methods}

The focused question of our study was to compare the root-coverage outcomes of a partially exposed CTG technique with those of a fully covered CTG technique. The patient, intervention, comparison, outcome (PICO) question that was used in the study had the following components: $P$, healthy patient with a Miller Class I/II gingival recession; I, root-coverage procedures for treating gingival recession using CTG; and C, the effect of using a partially exposed CTG technique on root-coverage outcomes in comparison with a fully covered CTG technique. The primary outcome was the difference, between the two techniques, in the amount of keratinized tissue gained. The secondary outcomes that were analyzed were any difference of other soft-tissue parameters recorded by the included studies. These included: reduction of recession width and depth; percentage of surgical sites achieving complete root coverage; percentage of recession coverage; gain of tissue biotype; changes of probing depth; and gain of clinical attachment level.

Electronic and manual searches in the dental literature up to February $28^{\text {th }}, 2017$, were performed by two independent reviewers (A.D. and J.G.) in four databases: PubMed; EMBASE; Web of Science; and Cochrane Central Register of Controlled Trials. For the PubMed-MEDLINE library, the search terms used were: ('gingival defect' [all] OR 'recession' [all]) AND ('exposed' [all] OR 'uncovered' [all] OR 'epithelial collar' [all] OR 'collar' [all]). For all other databases, the combination of keywords such as 'recession' AND 'exposed' were used. The screening in such databases was limited to 'clinical studies' AND 'humans'. In addition, a search for references in the included papers was performed. Finally, a hand search (January $1^{\text {st }}, 2016$, up to March $31^{\text {st }}, 2017$ ) was carried out in the following dental journals, Clinical Advances in Periodontics, Journal of Dental Research, Journal of Clinical Periodontology, Journal of Periodontology, European Journal of Oral Sciences, and The International Journal of Periodontics and Restorative Dentistry. This systematic review was registered on the PROSPERO website (registration number: CRD42017059601).

The inclusion criteria for articles were as follows: human-based; randomized controlled trial (RCT), pilot study, or case series in which soft-tissue outcomes were reported; a minimum of 10 defects in each study group; and a follow-up period of at least 3 months after the root-coverage procedures. Exclusion criteria were: animal study; case report; less than 3-month follow-up; sample size of less than 10 sites per study group; and/or incomplete or insufficient data on soft-tissue changes. 


\section{Data extraction and analyses}

Data were extracted by two independent reviewers (A.D. and J.G.). If necessary, any disagreement was resolved by discussion with a third examiner (G.L.). The pooled weighted mean difference (WMD) of each recorded parameter and the risk ratio of achieving complete root coverage between the two techniques were estimated using a computer program (RevMan version 5.0; The Nordic Cochrane Centre, The Cochrane Collaboration, Copenhagen, 2008). To avoid potential bias from data analysis, only RCTs were pooled in quantitative synthesis (metaanalyses).

The contribution of each article was weighed. Heterogeneity was assessed using a chi-square test and the $I^{2}$ statistic, the values of which range between $0 \%$ and $100 \%$ and where lower values represent less heterogeneity. If an analysis presented low heterogeneity, fixed-effects metaanalysis was subsequently applied. If an analysis presented high heterogeneity, random effects meta-analysis was applied. Forest plots were generated to assess the differences for all included studies using surgical sites as the analysis unit. A value of $P<0.05$ was used as the level of significance. The data presented in this systematic review adhered to the Preferred Reporting Items for Systematic Review and Meta-Analyses (PRISMA) statement $\underline{19}$.

The criteria used to assess the quality of the selected RCTs were modified from the RCT checklist of the Cochrane Center $\underline{20}$, which provided guidelines for sequence generation, allocation concealment method, masking of the examiner, addressing incomplete outcome data, and being free of selective outcome reporting. For non-RCTs, the Methodological Index for Non-Randomized Studies (MINORS) was used to rank the risk of bias of the included study $\underline{21}$. The degree of bias was categorized as low risk if all the criteria were met, as moderate risk when only one criterion was missing, and as high risk if two or more criteria were missing. Two independent reviewers (A.D. and G.L.) evaluated all the included articles.

\section{Results}

\section{Study selection and characteristics of included studies}

Initial screening of electronic databases yielded a total of 394 articles. In addition, seven more articles were selected through manual screening and other electronic sources. After elimination of duplicate studies, a total of 396 titles and abstracts were further evaluated. Overall, after screening of titles and abstracts, a total of 12 potentially relevant articles were selected. Full-text copies of these studies were obtained and thoroughly evaluated. Of these, five articles $\underline{22-26}$ fulfilled the inclusion criteria and were included in this systematic review (Fig. 1). Table 1 reports the seven articles excluded $27-33$ and the reasons for their exclusion. The kappa value between the two reviewers was 0.80 for evaluation of the titles and abstracts and 1.00 for evaluation of the full text. 


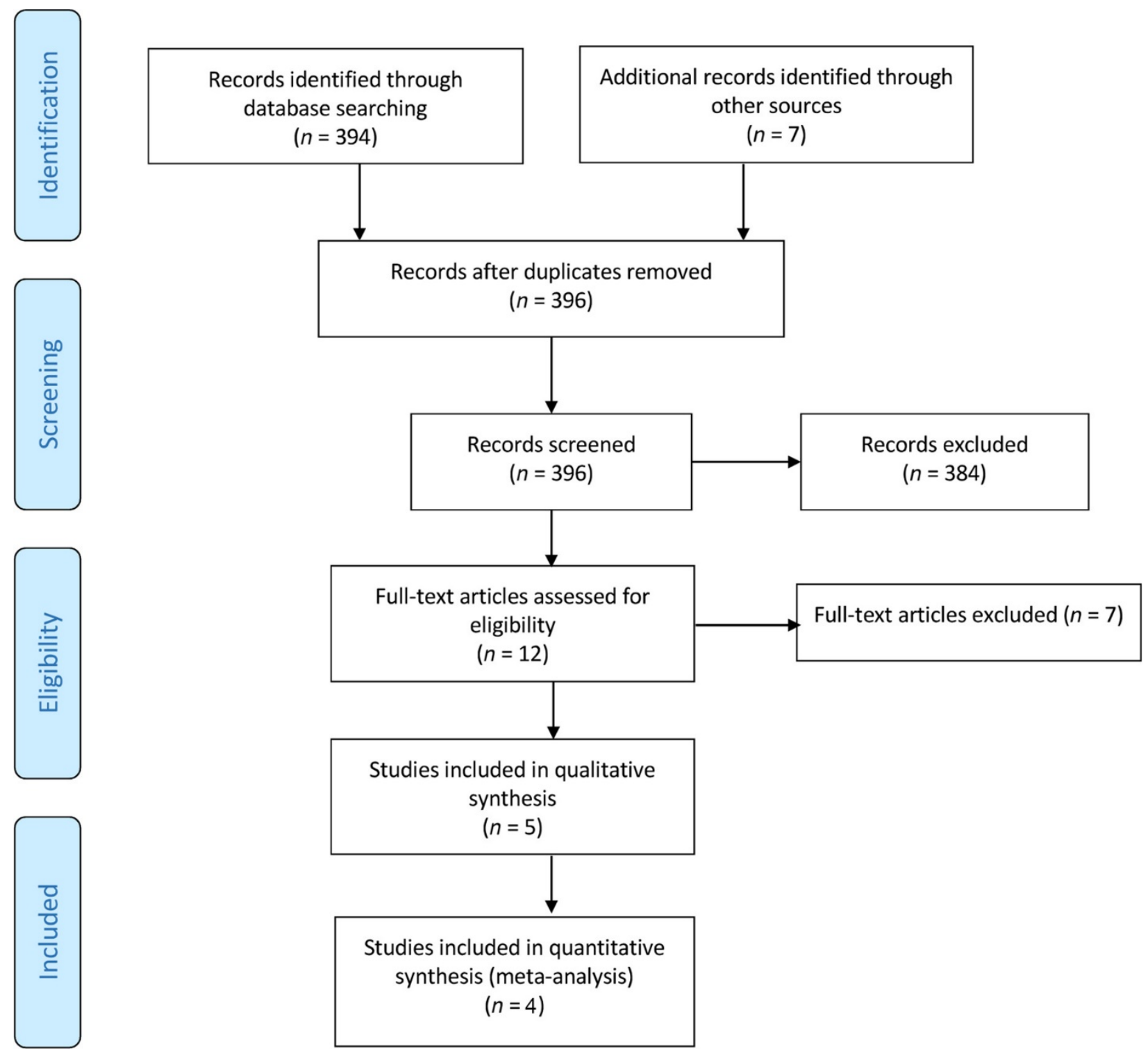

Figure 1 Preferred Reporting Items for Systematic Review and Meta-Analyses (PRISMA) flow chart demonstrates the selection process for inclusion of studies. 
Table 1. Articles excluded and the reasons for such exclusions

\begin{tabular}{|c|c|}
\hline Reasons for exclusion & Author(s)/Year (Ref) \\
\hline $\begin{array}{l}\text { Compared exposed CTG with FGG } \\
\text { instead of with fully covered CTG } \\
\\
\text { Included clinical outcome data } \\
\text { concerning partially exposed CTG as } \\
\text { a complication rather than an } \\
\text { intentionally exposed CTG }\end{array}$ & $\begin{array}{c}\text { Journée } 1989 \underline{\underline{27}} \\
\text { Boltchiet al. } 2000 \underline{28} \\
\text { Christgauet al. } 1997 \underline{29} \\
\text { Linget al. } 2003 \underline{30} \\
\text { Machteiet al. } 1995 \underline{31} \\
\text { Trombelliet al. } 1998 \underline{32} \\
\text { Zucchelliet al. } 1997 \underline{33}\end{array}$ \\
\hline
\end{tabular}

CTG, connective tissue graft; $F G G$, free gingival graft.

The characteristics of the five included articles $\underline{22-26}$ are summarized in Table $\underline{2}$. Among them, four $\underline{22}, \underline{23}, \underline{25}, \underline{26}$ were RCTs and one $\underline{24}$ was a retrospective case series. As a result of the different study design, the retrospective case series $\underline{24}$ was excluded from the meta-analyses but is still reported in Table $\underline{2}$. Two studies $\underline{22}, \underline{24}$ included smokers in their study protocol. The follow-up periods of the studies included ranged from 3 to 18 months. 
Table 2. Features of the included articles

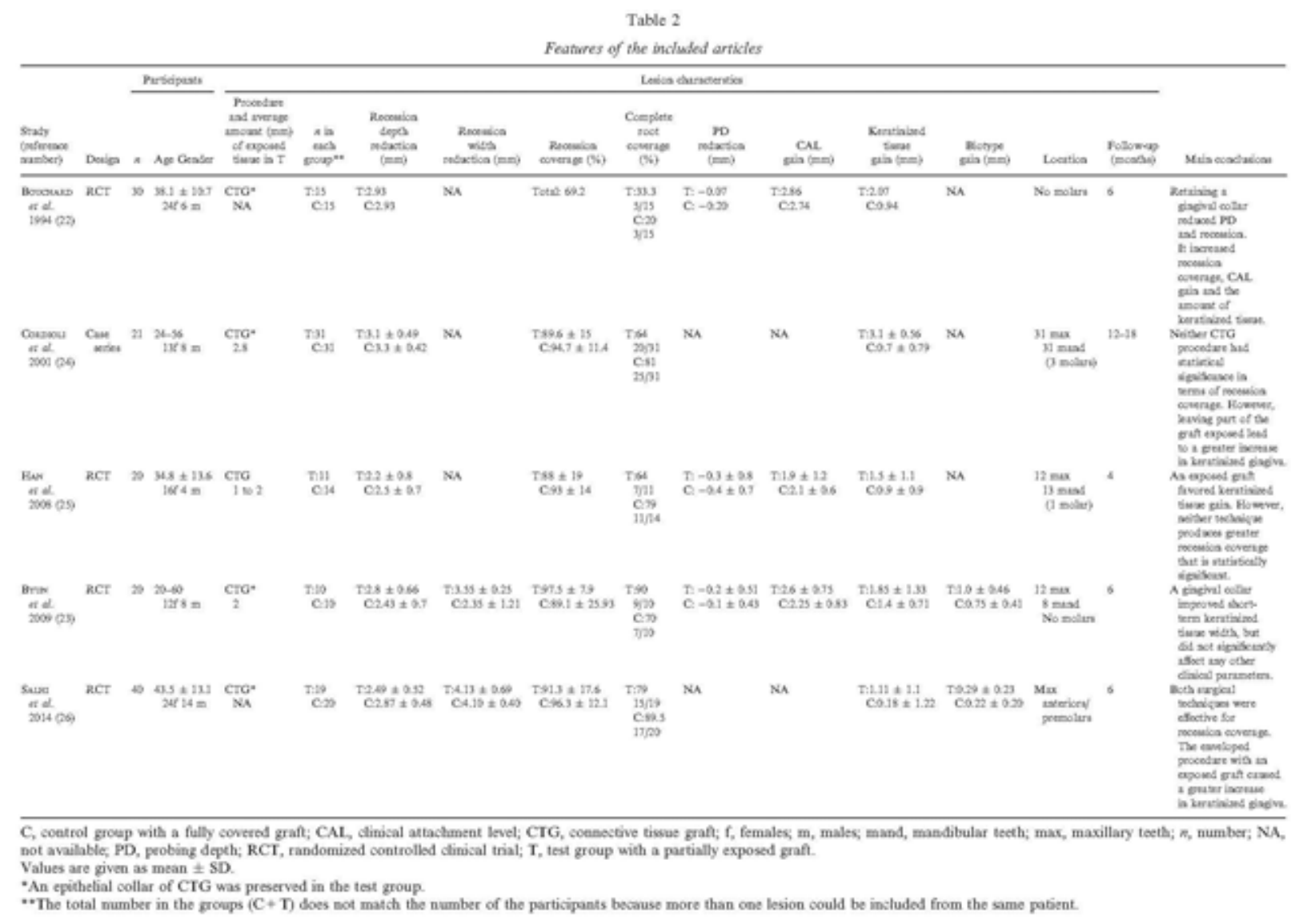

C, control group with a fully covered graft; CAL, clinical attachment level; CTG, connective tissue graft; $f$, females; m, males; mand, mandibular teeth; max, maxillary teeth; $n$, number; NA, not available; PD, probing depth; RCT, randomized controlled clinical trial; $T$, test group with a partially exposed graft.

Values are given as mean \pm SD.

a An epithelial collar of CTG was preserved in the test group.

$\mathrm{b}$ The total number in the groups $(\mathrm{C}+\mathrm{T})$ does not match the number of the participants because more than one lesion could be included from the same patient.

Four studies $\underline{22-25}$ included recession defects in both the maxilla and the mandible. The fifth study $\underline{26}$ included only maxillary defects as experimental sites. Four studies $\underline{22-25}$ treated systemically healthy individuals, with gingival defects classified as Miller Class I or Class II recessions. One of the studies $\underline{26}$ treated exclusively systemically healthy individuals with Miller Class I recession defects.

In each of the included studies, the root-coverage procedure performed was a CTG. In one of the study groups a portion of the graft (ranging from 1.0 to $3.8 \mathrm{~mm}$ ) was left exposed and in the other group a CAF was used to cover the graft. Four studies $\underline{22}-\underline{24}, \underline{26}$ preserved an epithelial collar on top of the exposed CTG. Among them, one study $\underline{24}$ introduced an 'envelope' technique for the lesions treated with an exposed CTG and a CAF for the lesions fully covered. Another study $\underline{26}$ used a 'pouch' technique for the lesions treated with an exposed CTG and a CAF for the lesions in the fully covered group. Finally, in one study $\underline{22}$, the exposed root surfaces in the fully covered group 
were conditioned with citric acid; however, there was no statistically significant effect of this additional step.

All the included studies $\underline{22}-\underline{26}$ reported recession depth, the percentage of recession coverage, the number of cases that achieved complete root coverage, and the gain in keratinized tissue width as treatment outcomes. Two studies $\underline{23}, \underline{26}$ reported recession width reduction and biotype gain as additional treatment outcomes. Three studies $\underline{22}, \underline{23}, \underline{25}$ reported gain in clinical attachment level and probing depth reduction as additional treatment outcomes.

\section{Meta-analyses of the included RCTs for the recorded parameters}

In terms of the amount of keratinized tissue, all the included RCTs $\underline{22}, \underline{23}, \underline{25}$, $\underline{26}$ reported, as outcome, the gain in keratinized tissue between the two techniques. However, one article $\underline{22}$ did not provide a standard deviation of the observations; therefore, it was excluded from the quantitative analysis. The results of meta-analyses showed a statistically significant gain in keratinized tissue in favor of the exposed graft group (WMD $=0.70 \mathrm{~mm}, 95 \% \mathrm{Cl}: 0.23-1.17 \mathrm{~mm}, P=0.003$, Fig. 2); a low heterogeneity was seen ( $P$ value for chi-square test $=0.70$ and $l^{2}=0 \%$ ) among the pooled studies.

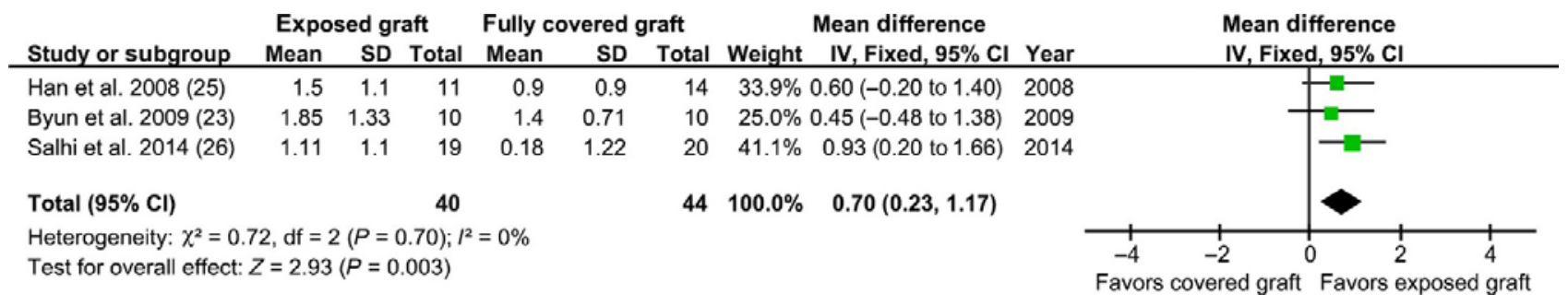

Figure 2 Gain of keratinized tissue width. A statistically significant difference of keratinized tissue gain in favor of the exposed graft technique [weighted mean difference (WMD) $=0.70 \mathrm{~mm}, 95 \% \mathrm{Cl}: 0.23-1.17 \mathrm{~mm}$, $P=0.003]$ was detected.

The three articles $\underline{23}, \underline{25}, \underline{26}$ reporting the outcome of recession-depth reduction showed no statistically significant difference of recession-depth reduction between the two techniques (WMD $=-0.23 \mathrm{~mm}, 95 \% \mathrm{Cl}:-0.48$ to $0.02 \mathrm{~mm}, P=0.07$, Fig. 3 ). However, lesions treated with a fully covered CTG technique showed a tendency to have greater recession-depth reduction. Moderate heterogeneity ( $P$ value for chi-square test $=0.09$ and $l^{2}=58 \%$ ) was seen among the pooled studies.

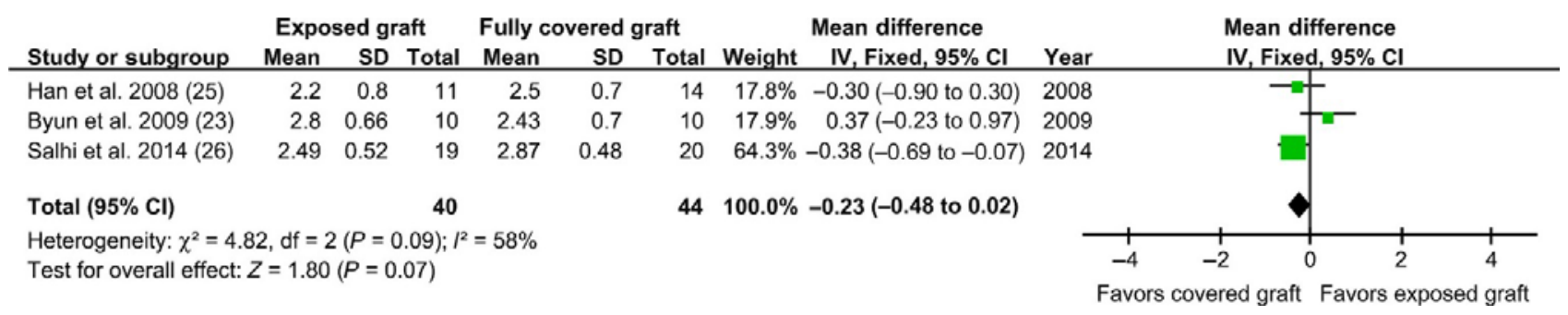

Figure 3 Recession depth reduction. No statistically significant difference was found for recession depth reduction, but a fully covered connective tissue graft (CTG) technique presented a tendency [weighted mean difference $(\mathrm{WMD})=-0.23 \mathrm{~mm}, 95 \% \mathrm{Cl}$ : -0.48 to $0.02 \mathrm{~mm}, P=0.07$ ] of more recession depth reduction. 
Two studies $\underline{23}, \underline{26}$ reported the outcomes of recession-width reduction between the two techniques. Meta-analysis showed no statistically significant difference (WMD $=0.56 \mathrm{~mm}, 95 \% \mathrm{Cl}:-0.58$ to $1.71 \mathrm{~mm}, P=0.33$, Fig. 4). A high degree of heterogeneity was seen ( $P$ value for chi-square test $=0.007$ and $l^{2}=86 \%$ ) between the pooled studies.

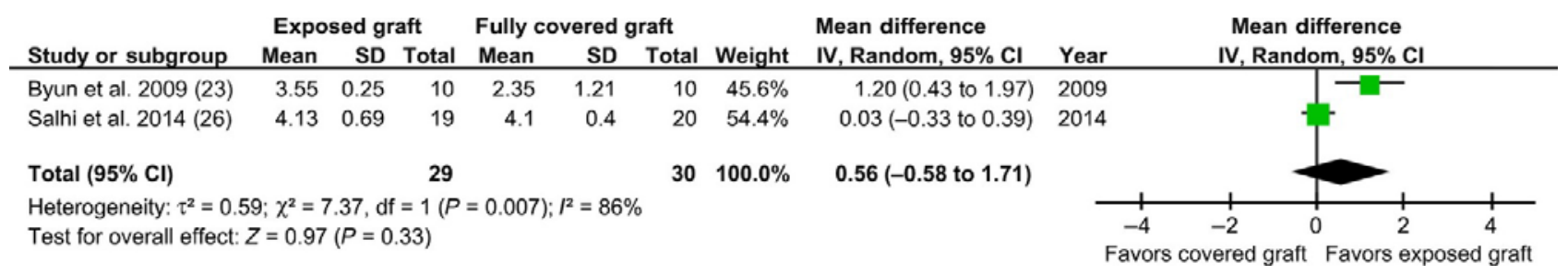

Figure 4 Recession width reduction. No statistically significant difference [weighted mean difference $(W M D)=0.56 \mathrm{~mm}, 95 \% \mathrm{Cl}:-0.58$ to $1.71 \mathrm{~mm}, P=0.33]$ was detected for recession width reduction.

All the included RCTs $\underline{22}, \underline{23}, \underline{25}, \underline{26}$ reported the number of participants achieving complete root coverage for both exposed and fully covered techniques. Of these studies, two $\underline{25}$, $\underline{26}$ reported a higher percentage of complete root coverage with the fully covered technique; the other two $\underline{22}, \underline{23}$ reported a higher percentage of complete root coverage with the exposed technique. The average of complete root coverage was $65.5 \%$ (range: $33.3-90.0 \%$ ) for the partially exposed CTG technique and $64.4 \%$ (range: $20.0-89.5 \%$ ) for the fully covered CTG technique. Meta-analysis for the comparison of complete root coverage between the two techniques presented a similar outcome (risk ratio $=1.00,95 \% \mathrm{Cl}: 0.80-1.24, P=0.98$, Fig. $\underline{5}$ ) for both interventions. The comparison presented a low heterogeneity among the selected studies ( $P$ value for chi-square test $=0.44$ and $\left.l^{2}=0 \%\right)$.

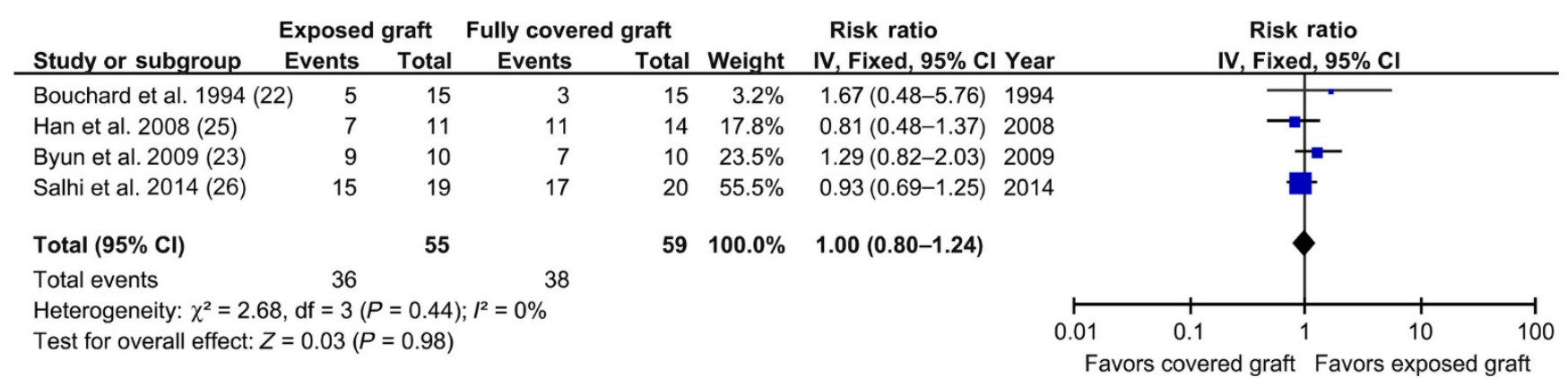

Figure 5 Complete root coverage. No statistically significant difference of risk ratio (risk ratio $=1.00,95 \% \mathrm{Cl}$ : $0.80-1.24, P=0.98$ ) to achieve complete root coverage was detected between the two techniques.

Three RCTs $\underline{23}, \underline{25}, \underline{26}$ reported the percentage of recession coverage between the two techniques. Meta-analysis showed no statistically significant difference (WMD $=-2.64 \%, 95 \% \mathrm{Cl}:-9.69 \%$ to $4.41 \%, P=0.46$, Fig. $\underline{6}$ ) between the two techinques. Low heterogeneity was seen ( $P$ value for chisquare test $=0.37$ and $I^{2}=1 \%$ ) among the pooled studies. 


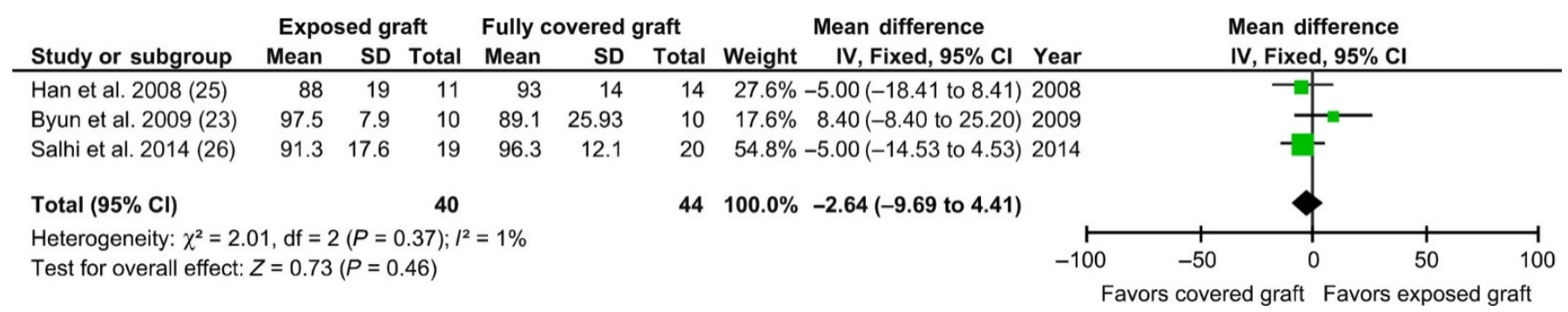

Figure 6 Percentage recession coverage. No statistically significant difference was found for percentage of recession coverage [weighted mean difference $(\mathrm{WMD})=-2.64 \%, 95 \% \mathrm{Cl}:-9.69$ to $4.41 \%, P=0.46$ ] between the two techniques.

For the change of tissue biotype $\underline{23}, \underline{26}$, probing depth reduction $\underline{23}, \underline{25}$, and clinical attachment level gain $\underline{23}, \underline{25}$, there were two studies reporting the outcomes for each parameter. Meta-analyses showed no statistically significant difference (for tissue thickness, WMD $=0.09 \mathrm{~mm}, 95 \% \mathrm{Cl}:-0.04$ to $0.22 \mathrm{~mm}, P=0.17$, Fig. $\underline{7}$; for probing depth reduction, WMD $=-0.04 \mathrm{~mm}, 95 \% \mathrm{Cl}:-0.38$ to $0.30 \mathrm{~mm}, P=0.84$, Fig. $\underline{8}$; for clinical attachment level gain, WMD $=0.11 \mathrm{~mm}, 95 \% \mathrm{Cl}:-0.41$ to $0.62 \mathrm{~mm}, P=0.69$, Fig. 9 ) between the two groups. Low heterogeneity was seen between the pooled studies for these three comparisons (for tissue thickness, $P$ value for the chi-square test $=0.38$ and $I^{2}=0 \%$; for probing depth reduction, $P$ value for chi-square test $=0.59$ and $I^{2}=0 \%$; and for clinical attachment level gain, $p$ value for chi-square test $=0.30$ and $l^{2}=7 \%$ ).

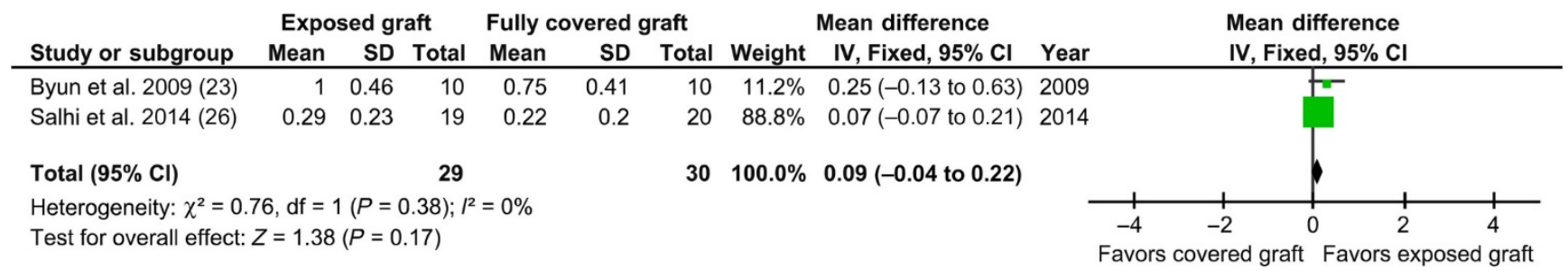

Figure 7 Tissue thickness. No statistically significant difference was detected for the comparisons of tissue thickness [weighted mean difference (WMD) $=0.09 \mathrm{~mm}, 95 \% \mathrm{Cl}:-0.04$ to $0.22 \mathrm{~mm}, P=0.17$ ].

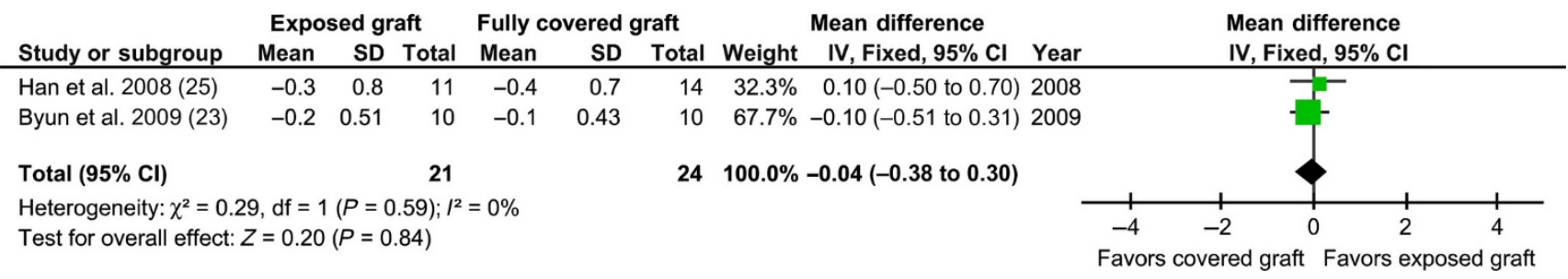

Figure 8 Pocket depth reduction. No statistically significant difference was detected for the comparisons of pocket depth reduction [weighted mean difference (WMD) $=-0.04 \mathrm{~mm}, 95 \% \mathrm{Cl}:-0.38$ to $0.30 \mathrm{~mm}, P=0.84$ ]. 


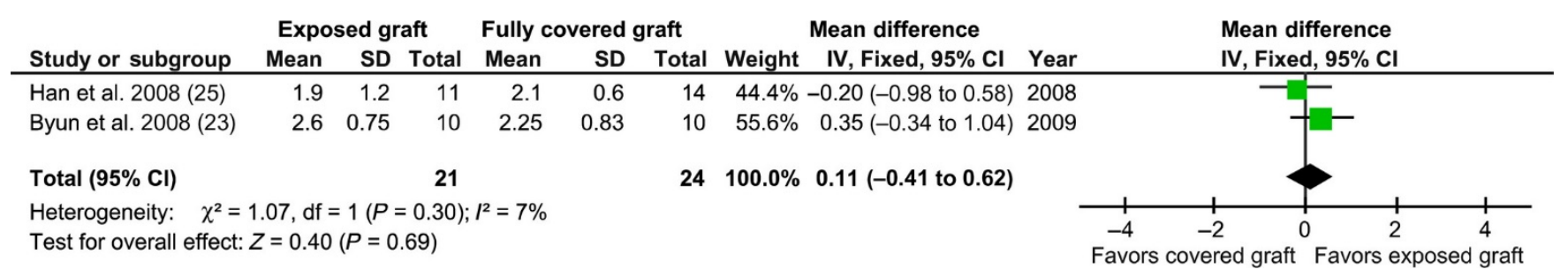

Figure 9 Clinical attachment level gain. No statistically significant difference was detected for the comparisons of clinical attachment level gain [weighted mean difference (WMD) $=0.11 \mathrm{~mm}, 95 \% \mathrm{Cl}:-0.41$ to $0.62 \mathrm{~mm}$, $P=0.69]$.

\section{Assessment of methodological quality}

The results of risk of bias assessment for the RCTs and non-RCT included are summarized in Tables $\underline{3}$ and $\underline{4}$, respectively. One study $\underline{23}$ was considered to have a low risk of bias. Another two studies $\underline{22}, \underline{25}$ were considered to have a moderate risk of bias. The other two studies $\underline{24}, \underline{26}$ had a high risk of bias. 
Table 3. Risk of bias assessment of the included randomized controlled clinical trials (RCTs)

\begin{tabular}{|c|c|c|c|c|}
\hline $\begin{array}{c}\text { Criteria } \\
\text { (Higgins \& } \\
\text { Green 2011) } \underline{20}\end{array}$ & $\begin{array}{c}\text { Bouchardet al. } \\
199422\end{array}$ & $\begin{array}{l}\text { Hanet al. } \\
2008 \underline{25}\end{array}$ & $\begin{array}{c}\text { Byunet al. } \\
2009 \underline{23}\end{array}$ & $\begin{array}{c}\text { Salhiet al. } \\
2014 \underline{26}\end{array}$ \\
\hline $\begin{array}{l}\text { Sequence } \\
\text { correctly } \\
\text { generated }\end{array}$ & Yes & Yes & Yes & Yes \\
\hline $\begin{array}{c}\text { Allocation } \\
\text { concealment } \\
\text { method reported }\end{array}$ & ? & ? & Yes & Yes \\
\hline $\begin{array}{l}\text { Examiner } \\
\text { masked }\end{array}$ & Yes & Yes & Yes & ? \\
\hline $\begin{array}{c}\text { All patients } \\
\text { accounted for at } \\
\text { end of study }\end{array}$ & Yes & Yes & Yes & No \\
\hline $\begin{array}{l}\text { Incomplete } \\
\text { outcome data } \\
\text { adequately } \\
\text { addressed }\end{array}$ & Yes & Yes & Yes & Yes \\
\hline $\begin{array}{c}\text { Free of } \\
\text { suggestion of } \\
\text { selective } \\
\text { outcome } \\
\text { reporting }\end{array}$ & Yes & Yes & Yes & Yes \\
\hline $\begin{array}{c}\text { Estimated } \\
\text { potential risk of } \\
\text { bias }\end{array}$ & Moderate & Moderate & Low & High \\
\hline
\end{tabular}

?, Not reported. 
Table 4. Risk of bias assessment for the included case series using the Methodological Index for Non-Randomized Studies (MINORS)

\begin{tabular}{|l|l|}
\hline Criteria (Slimet al. 2003) $\underline{\mathbf{2 1}}$ & $\begin{array}{l}\text { Cordioliet al. } \\
\mathbf{2 0 0 1} \mathbf{2 4}\end{array}$ \\
\hline A clearly stated aim & 2 \\
\hline Inclusion of consecutive patients & 2 \\
\hline Prospective collection of data & 1 \\
\hline End points appropriate to the aim of the study & 2 \\
\hline Unbiased assessment of the study end point & 2 \\
\hline Follow-up period appropriate to the aim of the study & 2 \\
\hline Loss to follow-up less than 5\% & 2 \\
\hline Prospective calculation of the study size & 0 \\
\hline Estimated potential risk of bias & High \\
\hline
\end{tabular}

$2=$ Adequate $1=$ Inadequate $0=$ Not reported .

\section{Discussion}

This systematic review was designed to evaluate the clinical outcomes (recession width, recession depth, percentage of recession coverage and complete root coverage, probing depth reduction, clinical attachment level gain, keratinized tissue gain, and biotype change) of two root-coverage techniques utilizing a partial or full-coverage CTG surgical technique. This scientific evidencebased review indicated that the use of a partially exposed CTG for root-coverage procedures could achieve a greater gain in keratinized gingiva, while a fully covered CTG might increase the amount of root coverage for the exposed root surface. Therefore, to optimize the outcomes of rootcoverage procedures, the clinician should select the appropriate surgical approach based on the intervention goals. If a gain in keratinized tissue is desired, a clinician can use a partially exposed CTG technique; if an increase in recession coverage and a reduction in recession depth are desired, a clinician can utilize a fully covered CTG technique.

The major strength of this systematic review is the number of clinical outcomes it compares between a partially exposed and a fully covered CTG technique. Also, the meta-analysis allows the authors to create a suggested clinical guideline in which the intervention goals of a root-coverage procedure should govern the surgical approach used. Nevertheless, there are several limitations in the current systematic review. The first limitation is the small number of studies included (only five). The second is that the influence of confounding factors on clinical outcomes between the groups in the present study cannot be validated. In the third, the current systematic review is limited in terms of the longevity of the recorded parameters as the longest follow-up period found was 18 months 24. Future studies should analyze the long-term outcomes, past 18 months, of the clinical parameters between the two surgical approaches.

A CTG procedure is considered as one of the most predictable methods to achieve root coverage 15. Different surgical techniques for the procedure have been identified in the literature. Langer \& Langer 34 proposed leaving a collar of epithelium attached to the CTG in order to create a more uniform gingival contour at the junction of the graft and natural gingiva. Raetzke 35 described a similar approach with an envelope technique, also leaving part of the epithelium in the middle portion of the graft. More recently, a CTG without an epithelial collar has been utilized in which a CAF is used in order to cover the graft $\underline{22}$. The aim of this fully covered design is to decrease the 
exposure of the graft to the oral cavity as well as to provide a better blood supply from the underlying periosteum and overlying flap. These techniques are the surgical techniques analyzed in this systematic review.

Previous RCTs $\underline{23}, \underline{25}$ and retrospective case series $\underline{24}$ have demonstrated that a partially exposed CTG results in a significantly greater increase in keratinized gingiva than a fully covered CTG. This systematic review had consistent findings. The increase in gingival width provides further support for utilizing a partially exposed CTG technique when the clinician's therapeutic goal is a gain in keratinized tissue. In a previously published article, Borghettiet al. $\underline{36}$ suggested that when an inadequate keratinized gingiva is present, full coverage of the CTG should be avoided. Our study finding supports the conclusion of Borghettiet al. $\underline{36}$ that a partially exposed graft does yield a greater increase in keratinized gingiva, which is beneficial for patients with keratinized gingiva of a minimal width.

The significance of tissue biotype on root coverage has been discussed in many studies $\underline{37}, \underline{38}$. A recent systematic review $\underline{39}$ concluded that there existed a significant correlation between flap thickness and root coverage, and a critical threshold thickness of $>1.1 \mathrm{~mm}$ was suggested from the analysis. However, in our study of exposed and fully covered CTG techniques, both CTG procedures demonstrated a significant increase in tissue thickness $\underline{23}, \underline{26}$ and further reduced patients' risk of future and recurrent gingival recession $\underline{40}$. Therefore, the initial tissue biotype should not be a factor to consider if an exposed graft will be used.

Our data demonstrate that there is no statistically significant difference in change of probing depth and clinical attachment level when utilizing an exposed or a fully covered CTG. Animal $\underline{41}$ and human $\underline{42}$ studies showed that attachment of CTG to the exposed root surface is mediated by a combination of epithelial downgrowth and connective tissue attachment following a CTG procedure. The soft-tissue healing process of partially and fully covered CTG is expected to be similar. Therefore, the difference in change of probing depth and clinical attachment level between the two groups was minimal.

Although the difference in recession-depth reduction between the two surgical approaches was not statistically significant, our study showed that a partially exposed CTG presented a tendency of less recession-depth reduction than a fully covered CTG. The authors speculate that this outcome might result from a relatively unfavorable blood supply to the uncovered portion of the graft $\underline{25}$.

Currently, there is a lack of consensus on how much graft can be left uncovered in a partially exposed CTG procedure without compromising clinical outcomes. Cordioloet al. $\underline{24}$ reported that $2.8 \pm 1.1 \mathrm{~mm}$ of graft could be left exposed; another two studies $\underline{23}, \underline{25}$ described an average amount of 1-2 $\mathrm{mm}$ of exposed graft. However, it is worth noting that the apical one-half to twothirds of the graft has to be covered by the flap to ensure survival of the exposed portion of the CTG $\underline{34}$. Future studies designed exclusively to determine the maximum amount of CTG that can be left exposed to the oral cavity would be beneficial to create a guideline for the partially exposed CTG technique.

In conclusion, the use of a partially exposed CTG in root-coverage procedures could achieve greater gain in keratinized gingiva, while a full-coverage CTG might be indicated for procedures aiming to reduce recession depth. In terms of the percentage of complete root coverage, no 
difference was seen between the two techniques. Therefore, clinicians should select the appropriate surgical approach based on the intervention goals to optimize the clinical outcomes.

\section{Conflicts of interest}

The authors do not have any financial interests, either directly or indirectly, in the products or information listed in the paper.

\section{References}

1 Kassab MM, Cohen RE. The etiology and prevalence of gingival recession. J Am Dent Assoc 2003; 134: 220-225.

2 Miller PD Jr. A classification of marginal tissue recession. Int J Periodontics Restorative Dent 1985; 5: 8-13.

3 Albandar JM, Kingman A. Gingival recession, gingival bleeding, and dental calculus in adults 30 years of age and older in the United States, 1988-1994. J Periodontol 1999; 70: 30-43.

4 Oates TW, Robinson M, Gunsolley JC. Surgical therapies for the treatment of gingival recession. A systematic review. Ann Periodontol 2003; 8: 303-320.

5 Hall WB. Present status of soft tissue grafting. J Periodontol 1977; 48: 587-597.

6 Hagewald S, Spahr A, Rompola E, Haller B, Heijl L, Bernimoulin JP. Comparative study of Emdogain and coronally advanced flap technique in the treatment of human gingival recessions. A prospective controlled clinical study. J Clin Periodontol 2002; 29: 35-41.

7 Grupe HE. Modified technique for the sliding flap operation. J Periodontol 1966; 37: 491-495.

8 Cohen DW, Ross SE. The double papillae repositioned flap in periodontal therapy. J Periodontol 1968; 39: 65-70.

9 Tarnow DP. Semilunar coronally repositioned flap. J Clin Periodontol 1986; 13: 182-185.

10 Sullivan $\mathrm{HC}$, Atkins JH. Free autogenous gingival grafts. I. Principles of successful grafting. Periodontics 1968; 6: 121-129.

11 Langer B, Calagna L. The subepithelial connective tissue graft. J Prosthet Dent 1980; 44: 363367.

12 Zabalegui I, Sicilia A, Cambra J, Gil J, Sanz M. Treatment of multiple adjacent gingival recessions with the tunnel subepithelial connective tissue graft: a clinical report. Int $\mathrm{J}$ Periodontics Restorative Dent 1999; 19: 199-206. 
13 Harris RJ. Root coverage with a connective tissue with partial thickness double pedicle graft and an acellular dermal matrix graft: a clinical and histological evaluation of a case report. $J$ Periodontol 1998; 69: 1305-1311.

14 McGuire MK, Scheyer ET, Nunn M. Evaluation of human recession defects treated with coronally advanced flaps and either enamel matrix derivative or connective tissue: comparison of clinical parameters at 10 years. J Periodontol 2012; 83: 1353-1362.

15 Chambrone L, Tatakis DN. Periodontal soft tissue root coverage procedures: A systematic review from the AAP Regeneration Workshop. J Periodontol 2015; 86: S8-S51.

16 Karring $\mathrm{T}$, Lang NP, Loe $\mathrm{H}$. The role of gingival connective tissue in determining epithelial differentiation. J Periodontal Res 1975; 10: 1-11.

17 Stetler KJ, Bissada NF. Significance of the width of keratinized gingiva on the periodontal status of teeth with submarginal restorations. J Periodontol 1987; 58: 696-700.

18 Nelson SW. The subpedicle connective tissue graft. A bilaminar reconstructive procedure for the coverage of denuded root surfaces. J Periodontol 1987; 58: 95-102.

19 Liberati A, Altman DG, Tetzlaff J, Mulrow C, Gøtzsche PC, loannidis JP, Clarke M, Devereaux PJ, Kleijnen J, Moher D. The PRISMA statement for reporting systematic reviews and metaanalyses of studies that evaluate health care interventions: explanation and elaboration. $J$ Clin Epidemiol 2009; 62: e1-e34.

20 Higgins JP, Green S. Cochrane Handbook for Systematic Reviews of Interventions Version 5.1.0 [updated March 2011]. The Cochrane Collaboration, 2011. Available from www.cochrane-handbook.org.

21 Slim K, Nini E, Forestier D, Kwiakowski F, Panis Y, Chipponi J. Methodological index for nonrandomized studies (MINORS): Development and validation of a new instrument. ANZ J Surg 2003; 73: 712-716.

22 Bouchard P, Etienne D, Ouhayoun JP, Nilveus R. Subepithelial connective tissue grafts in the treatment of gingival recessions. A comparative study of 2 procedures. J Periodontol 1994; 65: 929-936.

23 Byun HY, Oh TJ, Abuhussein HM, Yamashita J, Soehren SE, Wang HL. Significance of the epithelial collar on the subepithelial connective tissue graft. J Periodontol 2009; 80: 924932.

24 Cordioli G, Mortarino C, Chierico A, Grusovin MG, Majzoub Z. Comparison of 2 techniques of subepithelial connective tissue graft in the treatment of gingival recessions. $J$ Periodontol 2001; 72: 1470-1476.

25 Han JS, John V, Blanchard SB, Kowolik MJ, Eckert GJ. Changes in gingival dimensions following connective tissue grafts for root coverage: comparison of two procedures. $J$ Periodontol 2008; 79: 1346-1354. 
26 Salhi L, Lecloux G, Seidel L, Rompen E, Lambert F. Coronally advanced flap versus the pouch technique combined with a connective tissue graft to treat Miller's class I gingival recession: a randomized controlled trial. J Clin Periodontol 2014; 41: 387-395.

27 Journee D. Partially buried connective tissue grafts for gingival recession: Clinical results apropos of 22 cases. Journal de Parodontologie 1989; 8: 339-346.

28 Boltchi FE, Allen EP, Hallmon WW. The use of a bioabsorbable barrier for regenerative management of marginal tissue recession. I. Report of 100 consecutively treated teeth. $\mathrm{J}$ Periodontol 2000; 71: 1641-1653.

29 Christgau M, Bader N, Schmalz G, Hiller K-A, Wenzel A. Postoperative exposure of bioresorbable GTR membranes: effect on healing results. Clin Oral Investig 1997; 1: 109_ 118.

30 Ling LJ, Hung SL, Lee CF, Chen YT, Wu KM. The influence of membrane exposure on the outcomes of guided tissue regeneration: clinical and microbiological aspects. J Periodontal Res 2003; 38: 57-63.

31 Machtei EE, Dunford R, Grossi SG, Genco RJ. Gingival recession and exposure of barrier membrane: effect on guided tissue regeneration of Class II furcation defects. Int $\mathrm{J}$ Periodontics Restorative Dent 1995; 15: 590-599.

32 Trombelli L, Scabbia A, Tatakis DN, Checchi L, Calura G. Resorbable barrier and envelope flap surgery in the treatment of human gingival recession defects. J Clin Periodontol 1998; 25: 24-29.

33 Zucchelli G, de Sanctis M, Clauser C. Integrated connective tissue in bioabsorbable barrier material and periodontal regeneration. J Periodontol 1997; 68: 996-1004.

34 Langer B, Langer L. Subepithelial connective tissue graft technique for root coverage. J Periodontol 1985; 56: 715-720.

35 Raetzke PB. Covering localized areas of root exposure employing the "envelope" technique. $J$ Periodontol 1985; 56: 397-402.

36 Borghetti A, Glise JM, Monnet-Corti V, Dejou J. Comparative clinical study of a bioabsorbable membrane and subepithelial connective tissue graft in the treatment of human gingival recession. J Periodontol 1999; 70: 123-130.

37 Baldi C, Pini-Prato G, Pagliaro U, Nieri M, Saletta D, Muzzi L, Cortellini P. Coronally advanced flap procedure for root coverage. Is flap thickness a relevant predictor to achieve root coverage? A 19-case series. J Periodontol 1999; 70: 1077-1084.

38 Berlucchi I, Francetti L, del Fabbro M, Basso M, Weinstein RL. The influence of anatomical features on the outcome of gingival recessions treated with coronally advanced flap and enamel matrix derivative: a 1-year prospective study. J Periodontol 2005; 76: 899-907. 
39 Huang LH, Neiva RE, Wang HL. Factors affecting the outcomes of coronally advanced flap root coverage procedure. J Periodontol 2005; 76: 1729-1734.

40 Hwang D, Wang HL. Flap thickness as a predictor of root coverage: a systematic review. J Periodontol 2006; 77: 1625-1634.

41 Guiha R, Khodeiry SE, Mota L, Caffesse R. Histological evaluation of healing and revascularization of the subepithelial connective tissue graft. J Periodontol 2001; 72: 470478.

42 Bruno JF, Bowers GM. Histology of a human biopsy section following the placement of a subepithelial connective tissue graft. Int J Periodontics Restorative Dent 2000; 20: 225-231.

43 Kim DM, Neiva R. Periodontal soft tissue non-root coverage procedures: a systematic review from the AAP Regeneration Workshop. J Periodontol 2015; 86: S56-S72. 